\title{
Dual Corneal-Graft Rejection after mRNA Vaccine (BNT162b2) for COVID-19 during the First Six Months of Follow-Up: Case Report, State of the Art and Ethical Concerns
}

\author{
Matteo Nioi ${ }^{1, *, \dagger}$, Ernesto d'Aloja ${ }^{1}\left(\mathbb{D}\right.$, Maurizio Fossarello ${ }^{2}$ and Pietro Emanuele Napoli ${ }^{2, *, \dagger}$ \\ 1 Forensic Medicine Unit, Department of Medical Sciences and Public Health, University of Cagliari, \\ 09040 Cagliari, Italy; ernesto.daloja@unica.it \\ 2 Department of Surgical Sciences, Eye Clinic, University of Cagliari, 09124 Cagliari, Italy; \\ mfossarello@aoucagliari.it \\ * Correspondence: matteo.nioi@unica.it (M.N.); pietroemanuele.napoli@ca.omceo.it (P.E.N.); \\ Tel.: +39-349-086-8477 (M.N.); +39-320-864-3697 (P.E.N.) \\ + These authors contributed equally to this work.
}

Citation: Nioi, M.; d'Aloja, E.; Fossarello, M.; Napoli, P.E. Dual Corneal-Graft Rejection after mRNA Vaccine (BNT162b2) for COVID-19 during the First Six Months of Follow-Up: Case Report, State of the Art and Ethical Concerns. Vaccines 2021, 9, 1274. https://doi.org/ $10.3390 /$ vaccines 9111274

Academic Editors: Soo-Hong Lee, Hansoo Park, Jagathesh Chandra Rajendran and K. S. Jaganathan

Received: 15 September 2021

Accepted: 29 October 2021

Published: 3 November 2021

Publisher's Note: MDPI stays neutral with regard to jurisdictional claims in published maps and institutional affiliations.

Copyright: (c) 2021 by the authors. Licensee MDPI, Basel, Switzerland. This article is an open access article distributed under the terms and conditions of the Creative Commons Attribution (CC BY) license (https:// creativecommons.org/licenses/by/ $4.0 /)$.

\begin{abstract}
Present mass vaccination against Coronavirus Disease-19 (COVID-19) is the most widely used health policy and the most promising approach to curb the severe acute respiratory syndrome coronavirus 2 (SARS-CoV-2) pandemic globally. However, new side effects are emerging from the mass vaccination not described during the experimental stages. In the present study, we discuss a case of acute corneal graft rejection, which has occurred 25 years after transplantation and 13 days after the administration of the BNT162b2 vaccine (Comirnaty, BioNTech/Pfizer), which was followedup for a period of six months. In this period, the corneal inflammation appeared twice but was successfully managed with topical therapy and supplementation of Vitamin D. A risk of corneal graft rejection must be included in the list of potential vaccine complications, in order to inform the transplanted patient to undergo a preliminary and a follow-up ocular examination, and eventually to include corneal graft in the list of contraindications to vaccination.
\end{abstract}

Keywords: COVID-19; BNT162b2 vaccine; BNT162b2 vaccine side effect; COVID-19 vaccines corneal graft; COVID-19 vaccines transplant rejection; COVID-19 vaccines and corneal graft rejection; COVID19 immunomodulation; COVID-19 vaccines side effects; COVID-19 vaccines immunomodulation; COVID-19 vaccines vitamin D

\section{Introduction}

More than fifteen months after the outbreak of Coronavirus Disease-19 (COVID-19) pandemic, vaccines appear to be a promising approach for the resolution of the infection [1,2]. However, after the Food and Drug Administration (FDA) and the European Medicines Agency (EMA) granted the "emergency use authorization" of the COVID-19 vaccines developed by BioNTech/Pfizer and Moderna, numerous debates sprung up within the scientific community regarding the safety of the post-marketing phase, and side effects not described during the experimental stages [3-5]. A detailed description regarding the complications from the COVID-19 vaccines allows physicians, scholars, and patients to make a correct estimate of the risk-benefit ratio of vaccination and address the side effects immediately as they appear.

Recently, seven cases of both corneal lamellar and penetrating graft rejection following immunization against SARS-Cov-2 [6-10] (Table 1) have been described.

Although many studies confirm that the human eye represents a dual route of transmission for SARS-CoV-2, which is based on the presence of ACE2 receptors on the ocular surface, the phenomenon of corneal transplant rejection following vaccine administration is not completely understood [11-14]. Actually, several studies have also described cases 
of corneal graft rejection following the administration of influenza vaccines or yellow fever vaccines [15-20].

Table 1. Cases of corneal graft rejection after COVID-19 vaccination. COT-INT Cause of transplantation- Intervention; IIR: Interval intervention-rejection; IVR: Interval vaccine- rejection; F: female; M: male; CPB: Comirnaty, BNT162b2, BioNTech/Pfizer; DMEK: Descemet Membrane Endothelial Keratoplasty; FECD: Fuchs Endothelial Corneal Dystrophy; I $^{\circ}$ D: first dose; II ${ }^{\circ}$ D: second dose; TS: topical steroid; DEX: Dexamethasone; PK: penetrating keratoplasty; KC: keratoconus; RG: regraft; OP: oral prednisone; CCS: childhood corneal scar; CHA: ChAdO $\times 1 \mathrm{nCoV}-19$ Corona Virus Vaccine Recombinant COVISHIELD ${ }^{\mathrm{TM}}$, DSAEK: Descemet Stripping Automated Endothelial Keratoplasty; fDAEK: failed Descemet Stripping Automated Endothelial Keratoplasty; ACV: acyclovir.

\begin{tabular}{|c|c|c|c|c|c|c|c|c|c|}
\hline Study & $\mathbf{N}$ & COT-INT & Sex & Age & Vaccine & IIR & IVR & Therapy & Outcome \\
\hline \multirow{2}{*}{$\begin{array}{l}\text { Phylactou } \\
\text { et al., } 2021 \text { [6] }\end{array}$} & \multirow[b]{2}{*}{2} & DMEK for FECD & $F$ & 66 & $\mathrm{CPB}$ & 14 days & 7 days $\left(\mathrm{I}^{\circ} \mathrm{D}\right)$ & TS (DEX) & Full recovery \\
\hline & & $\begin{array}{l}\text { DMEK and cataract } \\
\text { surgery for FECD }\end{array}$ & $\mathrm{F}$ & 83 & $\mathrm{CPB}$ & 3 years & $\begin{array}{l}2 \text { months }\left(I^{\circ} \mathrm{D}\right) \\
3 \text { weeks }\left(I^{\circ} \mathrm{D}\right)\end{array}$ & TS (DEX) & Full recovery \\
\hline \multirow{2}{*}{$\begin{array}{l}\text { Wasser et al., } \\
2021 \text { [7] }\end{array}$} & \multirow{2}{*}{2} & $\begin{array}{l}\text { PK for KC } \\
\text { RG }\end{array}$ & M & 73 & $\mathrm{CPB}$ & 2 years & 13 days $\left(I^{\circ} \mathrm{D}\right)$ & $\mathrm{TS}(\mathrm{DEX})+\mathrm{OP}$ & Full recovery \\
\hline & & PK for KC & $\mathrm{M}$ & 56 & $\mathrm{CPB}$ & 10 months & 14 days $\left(I^{\circ} \mathrm{D}\right)$ & $\mathrm{TS}(\mathrm{DEX})+\mathrm{OP}$ & Full recovery \\
\hline $\begin{array}{l}\text { Ravichandran } \\
\text { et al., } 2021 \text { [8] }\end{array}$ & 1 & PK for CCS & M & 62 & $\mathrm{CHA}$ & 2 years & 3 weeks $\left(I^{\circ} \mathrm{D}\right)$ & TS & Unknown \\
\hline $\begin{array}{c}\text { Crnej et al., } \\
2021 \text { [9] }\end{array}$ & 1 & DMEK & M & 71 & $\mathrm{CPB}$ & 5 months & 7 days $\left(I^{\circ} D\right)$ & $\mathrm{TS}+\mathrm{OP}$ & Full recovery \\
\hline $\begin{array}{c}\text { K.I. Rallis } \\
\text { et al., } 2021 \text { [10] }\end{array}$ & 1 & $\begin{array}{l}\text { DSAEK for FECD; PK } \\
\text { for fDSAEK }\end{array}$ & M & 68 & CBP & 4 months & 4 Days $\left(I^{\circ} \mathrm{D}\right)$ & $\mathrm{TS}+\mathrm{ACV}$ & Full recovery \\
\hline
\end{tabular}

\section{Materials and Methods}

In the study, we described a single case observed and treated at the Eye Clinic of University of Cagliari, (San Giovanni di Dio Hospital).

\subsection{Clinical and Laboratory Assessment}

The patient performed the clinical and laboratory exams as follows: complete ophthalmological visit (visual acuity, intraocular pressure, slit-lamp biomicroscopy, fundus oculi), sampling of anterior chamber (AC) aqueous humor for reverse transcriptase-polymerase chain reaction (RT-PCR), complete blood count and vitamin D assay.

\subsection{Optical Coherence Tomography (OCT) Imaging}

Anterior OCT imaging was performed with Cirrus HD-OCT 4000; Carl Zeiss Meditec, Inc., Dublin, CA, USA. This device is a Fourier-domain OCT platform that has a $5 \mu \mathrm{m}$ axial resolution, takes 27,000 axial scans per second, and works at a wavelength of $840 \mathrm{~nm}$. The cross-sectional corneal images were obtained using the Anterior Segment 5 Line Raster scanning protocol (a set of five parallel lines of equal length at $3 \mathrm{~mm}$ ). Each scan line comprised 4096 A-scans.

This protocol was designed to identify alterations in the Anterior Segment, such as inflammatory floaters in AC (cells or proteins detectable in situations of corneal tissue inflammation, e.g., acute rejection).

\subsection{Informed Consent and Independent Review Board}

Written informed consent to publish this case report and the accompanying images were obtained from the patient.

Since only normal clinical practice is described in this case report, formal ethical approval by the Independent Review Board was not required in accordance with the policy of our Institution. 


\section{Case Report}

A 44-year-old Caucasian woman presented with a 2-day history of blurred vision, redness, and discomfort in her left eye, 13 days after receiving the first shot of the SARS-CoV-2 mRNA vaccine BNT162b2 (Comirnaty, Pfizer-BioNTech, Mainz, Germany). Systemic reactions were absent. The family anamnesis was unremarkable. The patient was unemployed. Medical history was unremarkable. Ocular history included penetrating keratoplasty (PK) performed 25 years before in her left eye due to keratoconus.

At presentation, her left best-corrected visual acuity (BCVA) was counting fingers, compared to 20/30 recorded six months before. Intraocular pressure was $12 \mathrm{~mm} \mathrm{Hg}$. Slit-lamp biomicroscopy revealed ciliary injection, diffuse corneal edema within the graft, keratic precipitates, Descemet folds, and anterior chamber (AC) cells were noted, indicating corneal graft rejection. The right eye was unremarkable. Fundus examination was normal in both eyes. Anterior segment OCT confirmed a series of morphological changes (corneal thickening, subepithelial bullae, internal cornea folds, hyper-reflective points in AC, irregularities of the endothelium). Central corneal thickness (CCT) was $692 \mu \mathrm{m}$, compared to $560 \mu \mathrm{m}$ of a previous visit (Figure 1). An AC aqueous sample was examined by polymerase chain reaction (PCR), and it was negative for cytomegalovirus, herpes simplex virus, and varicella-zoster virus. The complete blood count was normal. However, a severe vitamin $\mathrm{D}$ deficiency (circulating 25-hydroxyvitamin $\mathrm{D}[25(\mathrm{OH}) \mathrm{D}]$ concentration of $9 \mathrm{ng} / \mathrm{mL}$ ) was detected. (Table 2).

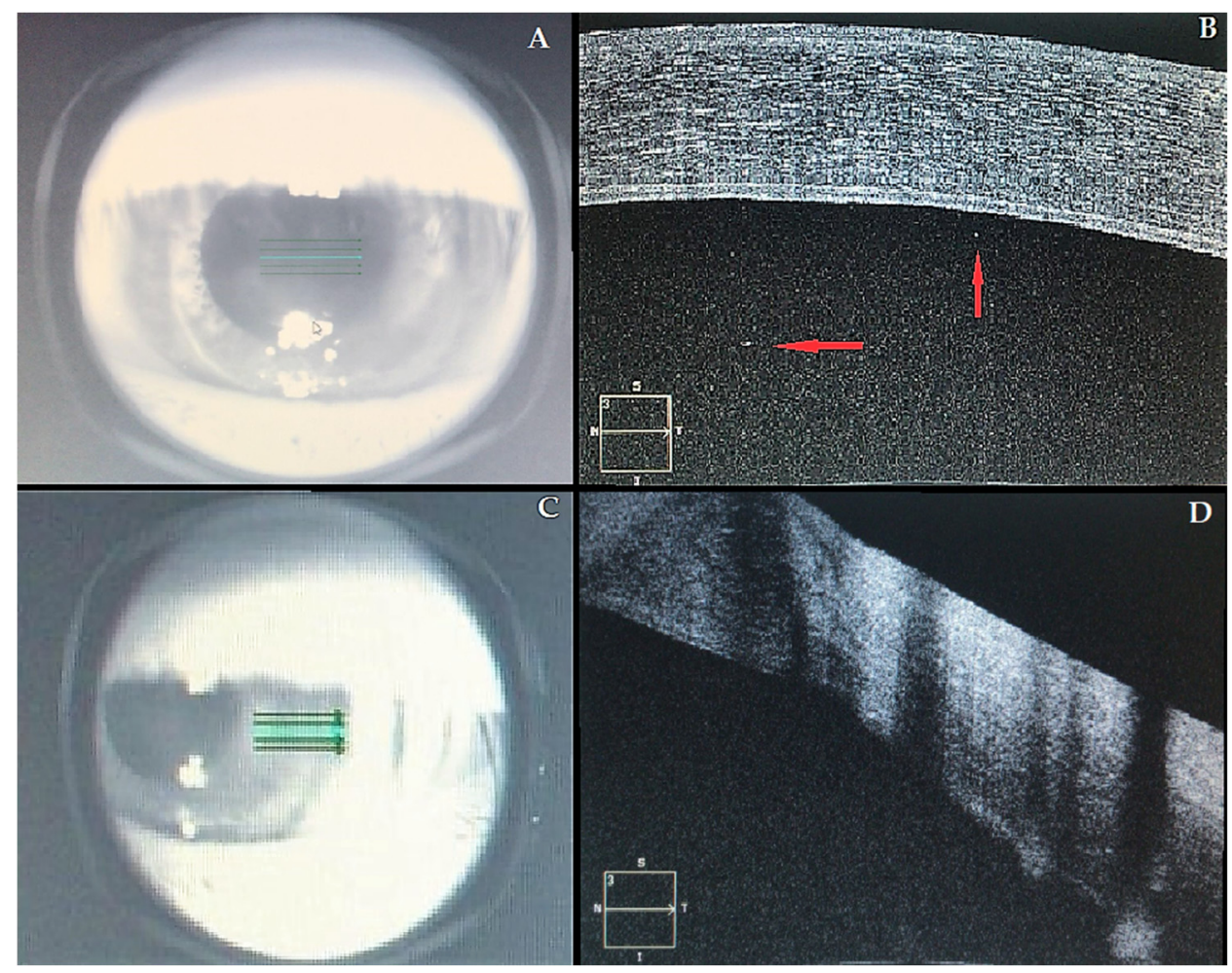

Figure 1. Acute corneal graft. (A-C) Infrared images of the left eye; (B-D) correspondent OCT images. Central cornea (A,B): in Figure 1B, it is possible to observe a marked corneal edema and a series of morphological changes (see text). Red arrows indicate a number of inflammatory floaters in the anterior chambre. Transition area (C,D) between the recipient's cornea (normal thickness) and the graft (thickened by edema).

Treatment was initiated using hourly steroid drops, i.e., dexamethasone $0.2 \%\left(\right.$ LUXAZONE $^{\circledR}$, Allergan, Rome, Italy). In addition, a vitamin D supplement (cholecalciferol, DIBASE ${ }^{\circledR}$, Abiogen Pharma, Ospedaletto, Italy) was prescribed (daily intakes of $1000 \mathrm{IU}$ of vitamin D for 15 days). At 1-week follow-up, corneal clouding appeared improved, visual acuity was 
20/100, corneal edema was reduced $(\mathrm{CCT}=597 \mu \mathrm{m})$, and only rare keratic precipitates and AC cells were visible. Therefore, topical steroid treatment was slowly tapered. Two weeks later, further improvement of the corneal edema was revealed $(\mathrm{CCT}=578 \mu \mathrm{m})$, and the visual acuity returned to baseline. Four weeks after the onset of corneal graft rejection, no active inflammation $(C C T=562 \mu \mathrm{m})$ was detected, and the visual acuity remained 20/30.

Table 2. Blood exams of the patient. Abnormal data are indicated in bold.

\begin{tabular}{|c|c|c|c|}
\hline Blood Component & Abbreviation Used & Reference Range & SI Reference Range \\
\hline White blood cells & WBC & $4.8 \times 10^{9} / \mathrm{L}$ & $4.5-11.0 \times 10^{9} / \mathrm{L}$ \\
\hline Red blood cells & RBC & $3.7 \times 10^{12} / \mathrm{L}$ & Female: $3.5-5.5 \times 10^{12} / \mathrm{L}$ \\
\hline Hemoglobin & HGB & $1.93 \mathrm{mmol} / \mathrm{L}$ & Female: $1.86-2.48 \mathrm{mmol} / \mathrm{L}$ \\
\hline Hematocrit & HT & 0.40 & Female: $0.36-0.46$ \\
\hline Mean corpuscular volume & $\mathrm{MCV}$ & $93 \mathrm{fl}$ & $80-100 \mathrm{fl}$ \\
\hline Mean corpuscular hemoglobin & $\mathrm{MCH}$ & $0.45 \mathrm{fmol} /$ cell & $0.39-0.54 \mathrm{fmol} /$ cell \\
\hline Mean corpuscular hemoglobin concentration & $\mathrm{MCHC}$ & $4.97 \mathrm{mmol} \mathrm{Hb} / \mathrm{L}$ & $4.81-5.58 \mathrm{mmol} \mathrm{Hb} / \mathrm{L}$ \\
\hline Platelets & Platelets & $239 \times 10^{9} / \mathrm{L}$ & $150-400 \times 10^{9} / \mathrm{L}$ \\
\hline \multicolumn{4}{|c|}{ Metabolic And Electrolyte Panel } \\
\hline Blood urea nitrogen & BUN & $10 \mathrm{mg} / \mathrm{dL}$ & $6-20 \mathrm{mg} / \mathrm{dL}$ \\
\hline Creatinine & Cre & $1.0 \mathrm{mg} / \mathrm{dL}$ & Female: $0.6-1.1 \mathrm{mg} / \mathrm{dL}$ \\
\hline Glucose & Glu & $89 \mathrm{mg} / \mathrm{dL}$ & 70-99 mg/dL \\
\hline Calcium & $\mathrm{Ca}+$ & $8.6 \mathrm{mg} / \mathrm{dL}$ & $8.6-10.2 \mathrm{mg} / \mathrm{dL}$ \\
\hline Sodium & $\mathrm{Na}+$ & $140 \mathrm{mEq} / \mathrm{L}$ & $136-145 \mathrm{mEq} / \mathrm{L}$ \\
\hline Potassium & $\mathrm{K}+$ & $4.2 \mathrm{mEq} / \mathrm{L}$ & $3.5-5.1 \mathrm{mEq} / \mathrm{L}$ \\
\hline Chloride & $\mathrm{Cl}-$ & $101 \mathrm{~m} \mathrm{Eq} / \mathrm{L}$ & 98-107 mEq/L \\
\hline 25-hydroxyvitamin D [25(OH)D] & Vit. D & $9 \mathrm{ng} / \mathrm{ml}$ & $20-40 \mathrm{ng} / \mathrm{ml}$ \\
\hline \multicolumn{4}{|c|}{ RT-PCR } \\
\hline Exam & & Result & \\
\hline Acqueous IgG/IgM cytomegalovirus (CMV) & & Negative & \\
\hline Acqueous IgG/IgM herpes simplex virus (HSV) & & Negative & \\
\hline Acqueous IgG/IgM varicella-zoster virus (VZV) & & Negative & \\
\hline
\end{tabular}

At a 4-week follow-up, a further episode of rejection in her left eye was observed, in parallel with persistence of vitamin D deficiency (serum [25(OH)D] of $19 \mathrm{ng} / \mathrm{mL}$ ). The corneal clinical picture was similar to previous episode. Steroid drops were re-started, and higher doses of vitamin D were prescribed (50,000 IU of vitamin D three times weekly). The corneal inflammation regressed in four weeks, and at six-months of follow-up, no further rejection episodes were observed. Nonetheless, in agreement with her GP, the patient refused to receive the second dose of the vaccine.

\section{Discussion}

The current report describes a case of biphasic acute corneal allograft rejection following a penetrating keratoplasty (PK) performed twenty-five years earlier, occurring approximately two weeks after the BNT162b2 (Comirnaty, BioNTech/Pfizer, Mainz, Germany ) vaccine administration. To our knowledge, this is the first case report regarding a similar adverse event that evaluates a follow-up period of six months in parallel with a vitamin D blood assay.

Overall, of the seven cases reported of corneal rejection following COVID-19 vaccination so far in the literature, the most frequently reported corneal transplant types were 
Perforating Keratoplasty (PK) and Descemet Membrane Endothelial Keratoplasty (DMEK) (42.9\% and $42.9 \%$ of cases, respectively), while Descemet Stripping Automated Endothelial Keratoplasty (DSAEK) was found only in $14.2 \%$ of cases. Five of the seven individuals affected were men $(71.4 \%)$ and two were women $(28.6 \%)$. The mean age was $68 \pm 8.1$ years. The vaccine most frequently associated with corneal rejection was the BNT162b2 (85.8\% of cases). The adverse event developed on average at $14.8 \pm 12.3$ months after surgery. The average interval between the execution of the vaccine and the occurrence of rejection was $14.9 \pm 8.8$ days. In $100 \%$ of cases, the therapy consisted of ocular steroids drops (TS). In three of seven cases $(42.9 \%)$, corticosteroids therapy with oral prednisone (OP) was associated with the TS; in one case (14.2\%), Acyclovir was associated with TS. In six cases $(85.8 \%)$, there was a complete recovery; in one case $(14.2 \%)$, the outcome is unknown.

\subsection{Causality}

Although it is difficult to demonstrate the causality between COVID-19 vaccine and corneal graft rejection, our case shows a temporal association between the two events. Moreover, a series of issues and criteria described in the specific guidelines (Causality Assessment of an Adverse Event Following Immunization-AEFI) suggests that this rare adverse event is likely due to immunization through a number of pathophysiological pathways [21].

From the first level of analysis (i.e., the evaluation of possible factors supporting the causal association), it is of particular importance the local immune tolerance (i.e., the relative immune privilege to the cornea from anterior chamber-associated immune deviationACAID) that has been maintained for 25 years after surgery. Moreover, considering the excellent state of health of the patient, we can exclude other possible etiological factors responsible for the rejection.

The second level of analysis concerns the description and the assessment of the casual association reported in the medical literature. Although there are a number of case reports that suggest a plausible biological relationship between the administration of the vaccine and the occurrence of the event, no high-level scientific evidence exists to confirm this relationship (e.g., meta-analyses) [6-10].

The third level of analysis regards the possibility that the event occurs within the time window of increased risk after a plausible cause. The thirteen-day lag between vaccine administration and corneal graft rejection that we observed falls within the window of increased risk described in the specific guidelines (AEFI) [21].

The fourth level of analysis (i.e., the evaluation of possible factors against a causal association) requires the proof of the absence of strong elements against a relationship between COVID-19 vaccination and the adverse event. Concerning this criterion, no strong elements indicate the absence of a causal link.

At the fifth level of analysis, AEFI guidelines recommend to evaluate other "qualifying factors" (i.e., previous similar episodes with or without vaccination, or exposure to drugs/allergens/over-the-counter products-OTCs). In our case report, no "qualifying factors" may be responsible for the rejection. In fact, after surgery for keratoconus, the patient had no other pathologies in progress (no drugs/no OTCs). Moreover, the patient had no previous reactions to vaccines, nor exposure to toxic substances.

\subsection{Possible Pathogenetic Mechanisms}

Although the mechanisms that lead to corneal transplant rejection have not been fully understood, the dysregulation of the immune system probably plays a crucial role, regardless of the genetic predisposition [22-26].

Phylactou et al. hypothesized several mechanisms concerning the pathogenesis of the allograft rejection. The first mechanism envisages the activation of the immune system following the vaccine, involving the occurrence of a direct allorecognition presumably by a direct pathway. The second possible mechanism predicts that antibodies play a central role in the dynamics of rejection (cross-reaction) [6]. Accordingly, COVID-19 vaccines have 
been shown to induce SARS-CoV-2 neutralizing antibodies and elicit strong Th1-biased CD4+ responses in humans. CD4+ Th1 cells have been shown to be the main mediators of corneal graft rejection [10]. Overall, corneal rejections after immunization are not a new phenomenon. An article of 1988 by Steinemann analyzed the problem of corneal transplant rejection after immunization. Among the etiological mechanisms hypothesized was local inflammation owing to the deposition of immune complexes, the pro-inflammatory action of interferon-gamma released at the systemic level, and that immunization may stimulate the production of $\mathrm{T}$ effector cells that cross-react with allo-major histocompatibility complex antigens of the corneal button [27]. Moreover, several immune-mediated reactions seem to determine other side effects of mRNA vaccines such as myocarditis, thrombocytopenia, and herpes zoster infection [28].

Future studies are required to enhance a greater understanding of these hypotheses concerning the COVID-19 mRNA vaccines.

Moreover, in our case, low values of vitamin D (which is an important fat-soluble secosteroid) may have facilitated and supported the adverse reaction.

The importance of verifying an adequate plasma level of vitamin D in transplant recipients is supported by an abundant and consolidated literature [29-34]. The molecular mechanism by which vitamin $\mathrm{D}$ inhibits transplant reaction is related to its immunomodulatory proprieties. In fact, cholecalciferol can decrease the expression of IL-2 and interferonmRNA, as well as reduce the proliferation and cytotoxic activity of $\mathrm{T}$ cells $\left(\mathrm{CD} 4^{+}\right.$and $\left.\mathrm{CD}^{+}\right)$. Moreover, vitamin $\mathrm{D}$ can suppress the expression of the major histocompatibility complexes of classes II, CD40, CD80, and CD86, thus decreasing differentiation, maturation, and immunostimulating capacity of dendritic cells that constitutively express the cholecalciferol Receptor and CYP27B1 [35-40].

Accordingly, the implementation of this vitamin was temporarily associated with the resolution of the corneal graft reject and the absence of further recurrences. This suggests the importance of monitoring vitamin D levels in the peri-vaccination period and in case of corneal transplant rejection.

\subsection{Peculiarities of the Case and Ethical Conundrum}

Some peculiarities in our case are consistent with those presented in the literature [6-10].

Firstly, this is primarily due to the time span between the transplants and the time of rejection (approximately 25 years).

Secondly, in comparison with other cases, our case describes a six-month follow-up period. This observation period has shown that, even after an initial resolution of the rejection, new episodes may arise that must be intercepted and treated early. These data are of absolute importance because they raise serious questions about the risk-benefit ratio of the second dose of vaccine after rejection following the first administration (in fact, the patient refused to receive the second dose of the vaccine). This point opens important ethical concerns that can only be addressed considering the deeper aspects of the immunologic mechanisms of rejection. Moreover, the administration of oral steroids can also represent an ethical dilemma as it reduces the ability of the immune system to produce an adequate level of antibodies against COVID-19 in a patient who is likely not to receive the second dose.

Thirdly, corneal graft rejection is described in our work for the first time after administration of COVID-19 vaccine with concomitant vitamin D deficiency. The latter clearly represents an important clue for immunological dysregulation (i.e., maladaptive changes in molecular control of immune system processes) that may have a fundamental role in the corneal rejection.

\subsection{Practical Implications}

This report suggests that, before vaccination, is of fundamental importance to collect a complete medical-history of the patient and to inform the latter regarding all the potential adverse effects of this injection. Thus, our case adds a piece to the puzzle of 
ocular adverse reactions from COVID-19 vaccines, and encourages the execution of laboratory/ophthalmological exams (e.g., serum levels of vitamin D), as well as a close follow-up after immunization. Clearly, a patient aware of this possible adverse event may be more inclined to check his/her medical condition. Considering the widespread use of COVID-19 vaccination, it is likely that further cases of corneal graft rejection will be reported in the next future [41,42].

If the causal relationship between corneal transplant rejection and COVID-19 vaccination will be confirmed in the scientific literature, the estimation of the risk/benefit ratio should be provided during the administration of the consent in order not to damage the patient's right to self-determination. In some countries, the doctor's failure to inform the patient about possible side effects of the vaccine can have medico-legal consequences [43].

Some authors hypothesized that, when rejection occurs, the administration of steroids through the local or oral route before the vaccine administration could be useful for preventive purposes [18]. Considering the pathogenesis of corneal graft rejection and the immunomodulatory effects of vitamin D deficiency in transplanted individuals, preventive check and integration of this vitamin could be considered before the vaccine administration.

\section{Conclusions}

Although corneal graft rejection after COVID-19 vaccination is still poorly understood, our case underlines the importance of a close follow-up after the onset of symptoms in these patients and a possible pathogenesis owing to an immune system dysregulation related to vitamin D deficiency. Future studies are needed to elucidate the mechanisms underlying potential transplant failure after immunization against SARS-CoV-2 and to clarify the epidemiological features of this complication.

Author Contributions: P.E.N. performed clinical evaluation; M.N. and P.E.N. developed the paper, and M.N., P.E.N., E.d. and M.F. contributed to the final version of the manuscript. E.d. and M.F. supervised the project. All authors have read and agreed to the published version of the manuscript.

Funding: This research received no external funding.

Institutional Review Board Statement: Since only normal clinical practice is described in this case report, formal ethical approval by the Independent Review Board was not required in accordance with the policy of our institution.

Informed Consent Statement: Written informed consent to publish this case report and the accompanying images were obtained from the patient.

Data Availability Statement: The data that support the findings of this study, after adequate anonymization that protects the patient's privacy, will be available on request from the corresponding authors (M.N. and P.E.N.). The data are not publicly available due to them containing information that could compromise research participant privacy/consent.

Conflicts of Interest: The authors declare no conflict of interest.

\section{References}

1. Giurgea, L.T.; Han, A.; Memoli, M.J. Universal coronavirus vaccines: The time to start is now. NPJ Vaccines 2020, 5, 1-3. [CrossRef] [PubMed]

2. Thiel, N.; Selwyn, C.; Murphy, G.; Simpson, S.; Chakrabarti, A.C. Recommendations for acceleration of vaccine development and emergency use filings for COVID-19 leveraging lessons from the novel oral polio vaccine. NPJ Vaccines 2021, 6, 1-8. [CrossRef]

3. Menni, C.; Klaser, K.; May, A.; Polidori, L.; Capdevila, J.; Louca, P.; Sudre, C.H.; Nguyen, L.H.; Drew, D.A.; Merino, J.; et al. Vaccine side-effects and SARS-CoV-2 infection after vaccination in users of the COVID Symptom Study app in the UK: A prospective observational study. Lancet Infect Dis. 2021, 21, 939-949. [CrossRef]

4. Muir, K.L.; Kallam, A.; Koepsell, S.A.; Gundabolu, K. Thrombotic thrombocytopenia after Ad26. COV2. S vaccination. NEJM 2021, 384, 1964-1965. [CrossRef]

5. Nioi, M.; Napoli, P.E.; Lobina, J.; Fossarello, M.; d'Aloja, E. COVID-19 and Italian healthcare workers from the initial sacrifice to the mRNA vaccine: Pandemic chrono-history, epidemiological data, ethical dilemmas, and future challenges. Front. Public Health 2020, 8, 591900 . 
6. Phylactou, M.; Li, J.P.O.; Larkin, D.F. Characteristics of endothelial corneal transplant rejection following immunisation with SARS-CoV-2 messenger RNA vaccine. Br. J. Ophthalmol. 2021, 105, 893-896.

7. Wasser, L.M.; Roditi, E.; Zadok, D.; Berkowitz, L.; Weill, Y. Keratoplasty Rejection After the BNT162b2 messenger RNA Vaccine. Cornea 2021, 40, 1070. [CrossRef] [PubMed]

8. Ravichandran, S.; Natarajan, R. Corneal graft rejection after COVID-19 vaccination. Indian J. Ophthalmol. 2021, 69, 1953-1954.

9. Crnej, A.; Khoueir, Z.; Cherfan, G.; Saad, A. Acute corneal endothelial graft rejection following COVID-19 vaccination. J. Fr. Ophtalmol. 2021, 69, 1953-1954.

10. Rallis, K.I.; Ting, D.S.; Said, D.G.; Dua, H.S. Corneal graft rejection following COVID-19 vaccine. Eye 2021, 1-2, Online ahead of print.

11. Napoli, P.E.; Nioi, M.; d'Aloja, E.; Fossarello, M. The ocular surface and the coronavirus disease 2019: Does a dual 'ocular route'exist? J. Clin. Med. 2020, 9, 1269. [CrossRef]

12. Roehrich, H.; Yuan, C.; Hou, J.H. Immunohistochemical study of SARS-CoV-2 viral entry factors in the cornea and ocular surface. Cornea 2020, 39, 1556-1562. [CrossRef] [PubMed]

13. Bal, S.; Chodosh, J.; Venkateswaran, N. Impact of SARS-CoV-2 on Ocular Surface Pathology and Treatment Practices: A Review. Curr. Ophthalmol. Rep. 2021, 1-6, Online ahead of print.

14. Napoli, P.E.; Nioi, M.; d'Aloja, E.; Fossarello, M. Safety recommendations and medical liability in ocular surgery during the COVID-19 pandemic: An unsolved dilemma. J. Clin. Med. 2020, 9, 1403. [CrossRef] [PubMed]

15. Matoba, A. Corneal Allograft Rejection Associated With Herpes Zoster Recombinant Adjuvanted Vaccine. Cornea 2021. Online ahead of print. [CrossRef] [PubMed]

16. Vignapiano, R.; Vicchio, L.; Favuzza, E.; Cennamo, M.; Mencucci, R. Corneal graft rejection after yellow fever vaccine: A case report. Ocul. Immunol. Inflamm. 2021, 1-4, Online ahead of print. [CrossRef] [PubMed]

17. Solomon, A.; Frucht-Pery, J. Bilateral simultaneous corneal graft rejection after influenza vaccination. Am. J. Ophthalmol. 1996, 121, 708-709. [CrossRef]

18. Wertheim, M.S.; Keel, M.; Cook, S.D.; Tole, D.M. Corneal transplant rejection following influenza vaccination. Br. J. Ophthalmol. 2006, 90, 925-926. [CrossRef]

19. Miedziak, A.I.; Tambasco, F.P.; Lucas-Glass, T.C.; Rapuano, C.J.; Laibsan, P.R.; Cohen, E.J. Evaluation of triggers for corneal graft rejection. Ophthalmic Surg. Lasers 1999, 30, 133-139. [CrossRef] [PubMed]

20. Solomon, A.; Siganos, C.S.; Frucht-Pery, J. Adverse ocular effects following influenza vaccination. Eye 1999, 13, 381-382. [CrossRef] [PubMed]

21. World Health Organization. Causality Assessment of an Adverse Event following Immunization (AEFI): User Manual for the Revised WHO Classification, 2nd ed.; 2019 update; World Health Organization: Geneva, Switzerland, 2019. Available online: https: / /apps.who.int/iris/handle/10665/340802 (accessed on 15 September 2021).

22. Caso, F.; Costa, L.; Ruscitti, P.; Navarini, L.; Del Puente, A.; Giacomelli, R.; Scarpa, R. Could Sars-coronavirus-2 trigger autoimmune and/or autoinflammatory mechanisms in genetically predisposed subjects? Autoimmun. Rev. 2020, $19,102524$. [CrossRef] [PubMed]

23. Bozkurt, B.; Kamat, I.; Hotez, P.J. Myocarditis with COVID-19 mRNA Vaccines. Circulation 2021, 144, 471-484. [CrossRef] [PubMed]

24. McShane, C.; Kiat, C.; Rigby, J.; Crosbie, Ó. The mRNA COVID-19 vaccine-a rare trigger of Autoimmune Hepatitis? J. Hepatol. 2021, 75, 1252-1254. [CrossRef] [PubMed]

25. Talotta, R. Do COVID-19 RNA-based vaccines put at risk of immune-mediated diseases? In reply to "potential antigenic crossreactivity between SARS-CoV-2 and human tissue with a possible link to an increase in autoimmune diseases". Clin. Immunol. 2021, 224, 108665. [CrossRef] [PubMed]

26. Fanni, D.; Saba, L.; Demontis, R.; Gerosa, C.; Chighine, A.; Nioi, M.; Suri, J.S.; Ravarino, A.; Cau, F.; Barcellona, D.; et al. Vaccine-induced severe thrombotic thrombocytopenia following COVID-19 vaccination: A report of an autoptic case and review of the literature. Eur. Rev. Med. Pharm. Sci. 2021, 25, 5063-5069.

27. Steinemann, T.L.; Bruce, H.K.; Jennings, C.D. Corneal allograft rejection following immunization. Am. J. Ophthalmol. 1988, 106, 575-578. [CrossRef]

28. Barda, N.; Dagan, N.; Ben-Shlomo, Y.; Kepten, E.; Waxman, J.; Ohana, R.; Hernán, M.A.; Lipsitch, M.; Kohane, I.; Netzer, D.; et al. Safety of the BNT162b2 mRNA Covid-19 vaccine in a nationwide setting. NEJM 2021, 385, 1078-1090. [CrossRef] [PubMed]

29. Adorini, L.; Penna, G.; Giarratana, N.; Roncari, A.; Amuchastegui, S.; Daniel, K.C.; Uskokovic, M. Dendritic cells as key targets for immunomodulation by Vitamin D receptor ligands. J. Steroid Biochem. Mol. Biol. 2004, 89, 437-441. [CrossRef]

30. Adorini, L.; Amuchastegui, S.; Daniel, K.C. Prevention of chronic allograft rejection by vitamin D receptor agonists. Immunol. Lett. 2005, 100, 34-41. [CrossRef] [PubMed]

31. Tahvildari, M.; Emami-Naeini, P.; Omoto, M.; Mashaghi, A.; Chauhan, S.K.; Dana, R. Treatment of donor corneal tissue with immunomodulatory cytokines: A novel strategy to promote graft survival in high-risk corneal transplantation. Sci. Rep. 2017, 7, 971. [CrossRef]

32. Reins, R.Y.; Baidouri, H.; McDermott, A.M. Vitamin D activation and function in human corneal epithelial cells during TLRinduced inflammation. IOVS 2017, 56, 7715-7727. [CrossRef] 
33. Napoli, P.E.; Nioi, M.; Fossarello, M. The "quarantine dry eye": The lockdown for coronavirus disease 2019 and its implications for ocular surface health. Risk Manag. Healthc Policy 2021, 14, 1629. [CrossRef] [PubMed]

34. Napoli, P.E.; Mangoni, L.; Gentile, P.; Braghiroli, M.; Fossarello, M. A panel of broad-spectrum antivirals in topical ophthalmic medications from the drug repurposing approach during and after the coronavirus disease 2019 era. J. Clin. Med. 2020, 9, 2441. [CrossRef]

35. De Luca, H.F.; Zierold, C. Mechanisms and functions of vitamin D. Nutr. Rev. 1998, 56, S4-S10. [CrossRef] [PubMed]

36. Courbebaisse, M.; Souberbielle, J.C.; Thervet, E. Potential nonclassical effects of vitamin D in transplant recipients. Transplantation 2010, 89, 131-137. [CrossRef]

37. Stein, E.M.; Shane, E. Vitamin D in organ transplantation. Osteoporos. Int. 2011, 22, 2107-2118. [CrossRef] [PubMed]

38. Lemire, J. 1, 25-dihydroxyvitamin D 3-a hormone with immunomodulatory properties. Z. Rheumatol. 2000, 59, I24-I27. [CrossRef] [PubMed]

39. Lemire, J.M. Immunomodulatory role of 1, 25-dihydroxyvitamin D3. J. Cell. Biochem. 1992, 49, 26-31. [CrossRef]

40. Courbebaisse, M. Vitamin D in Acute and Chronic Rejection of Transplanted Kidney. In Vitamin D in Chronic Kidney Disease; Ureña Torres, P., Cozzolino, M., Vervloet, M., Eds.; Springer: Berlin/Heidelberg, Germany, 2016.

41. Lee, E.H.; Li, J.Y. Immunization-Associated Corneal Transplantation Rejection: A Review. Cornea 2021. Online ahead of print. [CrossRef] [PubMed]

42. Shah, A.P.; Dzhaber, D.; Kenyon, K.R.; Riaz, K.M.; Ouano, D.P.; Koo, E.H. Acute Corneal Transplant Rejection After COVID-19 Vaccination. Cornea 2021. Online ahead of print. [CrossRef]

43. D'Aloja, E.; Finco, G.; Demontis, R.; Napoli, P.E.; Fossarello, M.; Nioi, M. COVID-19 and medical liability: Italy denies the shield to its heroes. EClinicalMedicine 2020, 25, 100470. [CrossRef] [PubMed] 